\title{
TOTAL ANTIOXIDANT ACTIVITY AND MANGANESE SUPEROXIDE DISMUTASE IN COMORBIDITY OF GASTROESOPHAGEAL REFLUX DISEASE AND AUTOIMMUNE THYROIDITIS IN STUDENT POPULATION
}

\author{
Tamara M. Pasiieshvili, Natalia M. Zhelezniakova, Lyudmila M. Pasiyeshvili, Olga M. Kovalyova \\ KHARKIV NATIONAL MEDICAL UNIVERSITY, KHARKIV, UKRAINE
}

\begin{abstract}
The aim: To determine the state of total antioxidant activity and the content of the mitochondrial enzyme - manganese superoxide dismutase in students with gastroesophageal reflux disease (GERD) and autoimmune thyroiditis (AIT) comorbidity.

Materials and methods: 120 patients with GERD and AIT, 45 patients with GERD and 42 patients with AIT were examined. The patients involved in the study were students. The international standardized GerdQ questionnaire was used. Total antioxidant activity and manganese superoxide dismutase levels were determined.

Results: The study showed that comorbidity of GERD and AIT was accompanied with a significant increase in the frequency and intensity of heartburn, sleep disorders and the use of additional medications to relieve symptoms. Patients with GERD and AIT had significantly lower total antioxidant activity than patients with isolated GERD and isolated AIT. At the same time, the manganese superoxide dismutase level was significantly higher in group with comorbidity than in patients with isolated diseases.

Conclusions: The presence of concomitant AIT in patients with GERD among the student population contributes to some deviations in the clinical characteristics, inhibition of total antioxidant activity and activation of manganese superoxide dismutase.
\end{abstract}

KEY WORDS: gastroesophageal reflux disease, autoimmune thyroiditis, students, total antioxidant activity, manganese superoxide dismutase

Wiad Lek. 2020;73(12 p. I):2644-2650

\section{INTRODUCTION}

Free radical oxidation of lipids in combination with an antioxidant system (AOS) form a highly mobile structure that provides stability of the cell membrane and realization of apoptosis in both physiological and pathological sense $[1,2,3]$. The processes of free radical lipid oxidation depend on the type of cells, the duration of their existence, the state of homeostasis triangle (central nervous, endocrine and immune systems) and development of pathological conditions - diseases of internal organs. Under normal conditions, this system is in equilibrium: phospholipids of the cell membrane are being constantly restored through their successive transformations to hydrogen peroxide, with its subsequent neutralization to water and oxygen $[1,2,3]$. This process is running under the control of AOS, which acts actively upon the receipt of antioxidants with food and their synthesis in the body. The emergence of diseases of internal organs causes the tension of the antioxidant defence system, which cannot be permanent, and its "overload» contributes to the formation of an unfavourable pathological link - endotoxicosis syndrome. That is, the «oxidative stress» arises, which causes the accumulation and oxidative damage of important biological macromolecules, such as DNA, fats and proteins, which leads to cell dysfunction, and further provokes aging $[3,4,5]$.
Antioxidant defence system has both enzymatic and non-enzymatic components, which are active during two phases of its operation. And if the first phase of the system is nonspecific (systemic), then the second phase of detoxification of xenobiotics (local level) occurs in the presence of the glutathione system enzymes and indicators of systemic and intracellular oxidative stress, in particular, manganese superoxide dismutase (MnSOD) [1,3,4,5,6].

MnSOD is a protein from the mitochondria-localized oxidoreductase family that acts as a second-phase AOS enzyme. Increasing the content of the indicated enzyme through the activation of Klotho protein synthesis has been shown to contribute to the control of the AOS system local level, that is, the process of apoptosis. Thus, raising MnSOD increases the resistance to oxidative stress, ie, «controls» the life span of the cell $[4,5,6]$.

Gastroesophageal reflux disease (GERD) and autoimmune thyroiditis (AIT) are quite common among the widespread internal organs diseases in young people. Their combination is due to the frequency of occurrence of both GERD and AIT. According to statistical calculations, GERD occurs in $20-40 \%$ of the world population, and almost $20 \%$ remain undiagnosed $[7,8,9]$. Prevalence of AIT among adults is $5-10 \%$, with a steady increase, especially among children and young people $[10,11,12,13]$. 
Table I. GerdQ questionnaire

\begin{tabular}{|c|c|c|c|c|c|c|}
\hline \multicolumn{2}{|c|}{ Group } & Questions & 0 days & 1 day & 2-3 days & 4-7 days \\
\hline \multirow[b]{2}{*}{ A } & 1 & How often did you have a burning feeling behind your breastbone (heartburn)? & 0 & 1 & 2 & 3 \\
\hline & 2 & $\begin{array}{l}\text { How often did you have stomach contents (liquid or food) moving upwards to } \\
\text { your throat or mouth (regurgitation)? }\end{array}$ & 0 & 1 & 2 & 3 \\
\hline \multirow{2}{*}{ B } & 3 & How often did you have a pain in the centre of the upper stomach? & 3 & 2 & 1 & 0 \\
\hline & 4 & How often did you have nausea? & 3 & 2 & 1 & 0 \\
\hline \multirow{2}{*}{$C$} & 5 & $\begin{array}{l}\text { How often did you have difficulty getting a good night's sleep because of your } \\
\text { heartburn and / or regurgitation? }\end{array}$ & 0 & 1 & 2 & 3 \\
\hline & 6 & $\begin{array}{l}\text { How often did you take additional medication for your heartburn and / or } \\
\text { regurgitation, other than what the physician told you to take? }\end{array}$ & 0 & 1 & 2 & 3 \\
\hline
\end{tabular}

The prerequisites for the formation of gastrointestinal tract diseases in the student population are malnutrition, unbalanced diet with predominance of fast foods in nutrition and a high prevalence of smoking.

The onset of autoimmune diseases is also quite often recorded at an early age, which is promoted by genetic predisposition, environmental triggers factor, disorders in the immune system against the background of frequent viral diseases; untimely or inadequate treatment of infectious pathology $[13,14]$. All this often happens against the backdrop of the evolution of the endocrine system, particularly during puberty that promotes the formation of various endocrinopathies [14].

\section{THE AIM}

Determine the state of total antioxidant activity and the content of the mitochondrial enzyme MnSOD in students with GERD and AIT comorbidity.

\section{MATERIALS AND METHODS}

The study was approved by the Ethics and Bioethics Committee of Kharkiv National Medical University (protocol 11, December 5, 2018). All the procedures of this study respect the ethical standards in the Helsinki Declaration of 1975, as revised in 2008, as well as the national law. Informed consent was obtained from all the patients included in the study.

The patients involved in the study belonged to the most active stratum of society - students. These patients were 18 to 25 years old and had a short history of the diseases (up to 3 years). The patients of the main group (120 persons) had GERD in combination with AIT. The comparison group consisted of 45 patients with GERD, who corresponded by age, gender, anamnesis history, and social affiliation to the patients in the main group. The patient groups were identical in age (21.9 \pm 2.7 and $21.2 \pm 2.4$ years, respectively), sex (93 (77.5\%) and 34 (75.5\%) women, respectively), education, form of GERD and disease duration. Another comparison group was represented by 42 patients with AIT, who were identical in terms of major indicators to the other two groups. The control group consisted of 20 practically healthy volunteers - students of the same age and sex.
When establishing the diagnosis of GERD, the recommendations of Montreal consensus (2006) [15], as well as local «Protocols for the management of patients...» with the specified disease were used. Determination of the lesion form of esophageal mucosa was performed during its visual examination in gastroscopy, using a video endoscopic system «Fuginon» (Japan), while establishing endoscopically negative GERD or «reflux esophagitis» according to the Los Angeles classification (1994). In 34 cases (28.3\%), the erosive damage of the esophagus was determined and in 86 cases the non-erosive $(71.7 \%)$. In the comparison group, erosive disease was found in $24.4 \%$ ( 11 persons) of cases.

The presence of AIT was confirmed based on the complaints, palpatory changes of the thyroid gland and ultrasound data (Mindray DC-60 Exp, China) by the standard protocol. AIT diagnosis was confirmed by the presence of antibodies to thyroperoxidase and thyroglobulin. The functional state of the thyroid gland was evaluated by the content of thyroid stimulating hormone, free thyroxine and free triiodothyronine. In all cases, the thyroid status corresponded to the euthyroid.

For the diagnosis of GERD and in order to evaluate its impact on the quality of life of patients, we used the international standardized GerdQ questionnaire [16], which was filled in by the patient and consisted of 6 questions (Tab I). It included three groups of questions: group $\mathrm{A}$ - heartburn and regurgitation - testify to the GERD diagnosis; group $\mathrm{B}$ - nausea and epigastric pain - manifestations that call into question GERD; group C - sleep disorders and administration of additional medication - questions about the impact of the disease on the quality of life, testifying to the benefit of GERD. Each of the 6 items of the scale is rated from 0 to 3 points, with symptoms characteristic of GERD: 0 is the absence of a symptom, 3 - its occurrence 4-7 times a week, and, conversely, for the manifestations uncharacteristic of GERD (nausea and epigastric pain): 3 - complete absence of symptoms, 0 - its presence within 4-7 days a week. The maximum possible GerdQ score is 18 . According to the recommendations, upon receipt of a total score of 8 and above, the patient is diagnosed with GERD.

To estimate smoking experience, the "pack/years" indicator was determined by the formula: the number of cigarettes smoked per day was multiplied by the smoking experience in years and divided by 20 . 
Table II. The frequency of the main complaints in the examined patients, $n, \%$

\begin{tabular}{|c|c|c|c|c|c|c|}
\hline \multirow[t]{2}{*}{ Symptom } & \multicolumn{2}{|c|}{$\begin{array}{l}\text { GERD and AIT } \\
(n=120)\end{array}$} & \multicolumn{2}{|c|}{$\begin{array}{c}\text { GERD } \\
(n=45)\end{array}$} & \multirow{2}{*}{$\begin{array}{l}\text { Significance of } \\
\text { differences }\left(x^{2}\right)^{1}\end{array}$} & \multirow{2}{*}{$\begin{array}{l}\text { Fisher's exact } \\
\text { test }\left(\varphi^{*}\right)^{2}\end{array}$} \\
\hline & $\mathbf{n}$ & $\%$ & $\mathbf{n}$ & $\%$ & & \\
\hline Heartburn & 120 & 100 & 45 & 100 & & \\
\hline Discomfort in the epigastric region & 27 & 22.5 & 6 & 13.3 & $\begin{array}{c}x 2=1.7188 \\
p=0.189\end{array}$ & $\varphi^{*}=1.379$ \\
\hline Pain in the epigastrium & 19 & 15.8 & 6 & 13.3 & $\begin{array}{c}x 2=0.1591 \\
p=0.689\end{array}$ & $\varphi^{*}=0.406$ \\
\hline Dysphagia & 8 & 6.7 & 2 & 4.4 & $\begin{array}{c}x 2=0.2839 \\
p=0.594\end{array}$ & $\varphi^{*}=0.578$ \\
\hline Nausea & 14 & 11.7 & 4 & 8.9 & $\begin{array}{c}x^{2}=0.2598 \\
p=0.610\end{array}$ & $\varphi^{*}=0.526$ \\
\hline Vomiting & 8 & 6.7 & 3 & 6.7 & $\begin{array}{c}x^{2}=0 \\
p=1\end{array}$ & $\varphi^{*}=0$ \\
\hline Belching & 63 & 52.5 & 6 & 13.3 & $\begin{array}{l}x 2=20.6343 \\
p<0.00001\end{array}$ & $\varphi^{*}=5$ \\
\hline Feeling of rapid satiety after eating & 41 & 34.2 & 11 & 24.4 & $\begin{aligned} x^{2} & =1.4333 \\
p & =0.231\end{aligned}$ & $\varphi^{*}=1.236$ \\
\hline Flatulence & 47 & 39.2 & 14 & 31.1 & $\begin{array}{c}x^{2}=0.9114 \\
p=0.339\end{array}$ & $\varphi^{*}=0.973$ \\
\hline Hoarseness of voice & 9 & 7.5 & 1 & 2.2 & $\begin{array}{c}x 2=1.6012 \\
p=0.206\end{array}$ & $\varphi^{*}=1.47$ \\
\hline Cough & 11 & 9.2 & 3 & 6.7 & $\begin{array}{c}x^{2}=0.2634 \\
p=0.607\end{array}$ & $\varphi^{*}=0.526$ \\
\hline
\end{tabular}

Note: ${ }^{1} p<0.05$ - the difference is statistically significant between groups;

${ }^{2}$ zone of significance at $p<0.05-$ more than 1.64 , at $p<0.01$ - more than 2.31 .

Table III. Frequency distribution of the main manifestations of GERD according to the GERD- $\mathrm{Q}$ questionnaire, $\mathrm{n}, \%$

\begin{tabular}{|c|c|c|c|c|c|c|c|c|c|c|}
\hline \multirow[t]{2}{*}{ Symptom } & & \multicolumn{4}{|c|}{$\begin{array}{l}\text { GERD and AIT } \\
(n=120)\end{array}$} & \multicolumn{4}{|c|}{$\begin{array}{c}\text { GERD } \\
(n=45)\end{array}$} & \multirow{2}{*}{$\begin{array}{l}\text { Significance of } \\
\text { differences }\left(x^{2}\right)^{1}\end{array}$} \\
\hline & & 0 days & 1 day & 2-3 days & 4-7 days & 0 days & 1 day & 2-3 days & 4-7 days & \\
\hline \multirow{2}{*}{ Heartburn } & $\mathrm{n}$ & 0 & 0 & 27 & 93 & 0 & 0 & 18 & 27 & \multirow{2}{*}{$\begin{array}{l}x^{2}=5.053 \\
p=0.025\end{array}$} \\
\hline & $\%$ & 0 & 0 & 22.5 & 77.5 & 0 & 0 & 40 & 60 & \\
\hline \multirow{2}{*}{ Regurgitation } & $\mathrm{n}$ & 11 & 35 & 43 & 31 & 7 & 5 & 19 & 14 & \multirow{2}{*}{$\begin{array}{l}x^{2}=6.315 \\
p=0.098\end{array}$} \\
\hline & $\%$ & 9.2 & 29.2 & 35.8 & 25.8 & 15.6 & 11.1 & 42.2 & 31.1 & \\
\hline \multirow{2}{*}{ Epigastric pain } & $\mathrm{n}$ & 101 & 11 & 8 & 0 & 39 & 5 & 1 & 0 & \multirow{2}{*}{$\begin{array}{l}x^{2}=1.337 \\
p=0.513\end{array}$} \\
\hline & $\%$ & 84.2 & 9.2 & 6.6 & 0 & 86.7 & 11.1 & 2.2 & 0 & \\
\hline \multirow{2}{*}{ Nausea } & $\mathrm{n}$ & 106 & 8 & 5 & 1 & 41 & 2 & 1 & 1 & \multirow{2}{*}{$\begin{array}{l}x^{2}=1.156 \\
p=0.764\end{array}$} \\
\hline & $\%$ & 88.3 & 6.7 & 4.2 & 0.8 & 91.1 & 4.5 & 2.2 & 2.2 & \\
\hline \multirow{2}{*}{$\begin{array}{c}\text { Sleep } \\
\text { disorders }\end{array}$} & $\mathrm{n}$ & 3 & 8 & 31 & 78 & 4 & 8 & 19 & 14 & \multirow{2}{*}{$\begin{array}{c}x 2=16.975 \\
p<0.001\end{array}$} \\
\hline & $\%$ & 2.5 & 6.7 & 25.8 & 65.0 & 8.9 & 17.8 & 42.2 & 31.1 & \\
\hline \multirow{2}{*}{$\begin{array}{l}\text { Additional } \\
\text { medications }\end{array}$} & $\mathrm{n}$ & 6 & 9 & 53 & 52 & 8 & 7 & 21 & 9 & \multirow{2}{*}{$\begin{array}{c}x 2=13.353 \\
p=0.04\end{array}$} \\
\hline & $\%$ & 5.0 & 7.5 & 44.2 & 43.3 & 17.8 & 15.6 & 46.6 & 20.0 & \\
\hline
\end{tabular}

Note: ${ }^{1} p<0.05$ - the difference is statistically significant between groups

Total antioxidant activity (TAA) in the serum of patients was determined by the photometric method on an automated chemistry analyzer «LabLine-80» (Austria) using a commercial test system produced by Elabscience (USA).

The activity of MnSOD was determined in the serum of patients by enzyme immunoassay on an automated EIA analyzer «LabLine-90» (Austria) using a commercial test system manufactured by Elabscience (USA).

Statistical data processing was performed using the software package Statistica Basic Academic 13 for Windows En, local. Methods of parametric and nonparametric statistics were used, results were considered reliable if $\mathrm{p}<0.05$. 
Table IV. Intensity of the main manifestations of GERD according to the GERD-Q questionnaire, points, $M \pm S D$

\begin{tabular}{|c|c|c|c|}
\hline Symptom & $\begin{array}{l}\text { GERD and AIT } \\
(n=120)\end{array}$ & $\begin{array}{c}\text { GERD } \\
(n=45)\end{array}$ & Significance of differences ${ }^{1}$ \\
\hline Heartburn & $2.78 \pm 0.42$ & $2.6 \pm 0.49$ & $p=0.03$ \\
\hline Regurgitation & $1.78 \pm 0.94$ & $1.89 \pm 1.03$ & $p=0.53$ \\
\hline Epigastric pain & $2.78 \pm 0.56$ & $2.84 \pm 0.42$ & $p=0.45$ \\
\hline Nausea & $2.83 \pm 0.53$ & $2.84 \pm 0.56$ & $p=0.83$ \\
\hline Sleep disorders & $2.53 \pm 0.73$ & $1.96 \pm 0.93$ & $\mathrm{p}<0.01$ \\
\hline Additional medications & $2.26 \pm 0.80$ & $1.69 \pm 0.99$ & $\mathrm{p}<0.01$ \\
\hline
\end{tabular}

Note: ${ }^{1} p<0.05$ - the difference is statistically significant between groups

Table V. Total antioxidant activity in the examined patients, $\mathrm{mmol} / \mathrm{l}$

\begin{tabular}{|c|c|c|c|}
\hline Groups & Total antioxidant activity, $\mathrm{mmol} / \mathrm{l}$ & $\begin{array}{l}\text { Significance of differences } \\
\text { compared with control group }\end{array}$ & $\begin{array}{c}\text { Significance of differences } \\
\text { between groups }\end{array}$ \\
\hline $\begin{array}{l}\text { GERD and AIT } \\
\qquad(n=120)\end{array}$ & $\begin{array}{c}305.257 \\
(160.189 ; 425.108) \\
\end{array}$ & $U=376, p<0.01$ & $\begin{array}{l}U_{1-2}=1557, p_{1-2}<0.01 \\
U_{1-3}=1736, p_{1-3}<0.01\end{array}$ \\
\hline $\begin{array}{c}\text { GERD } \\
(n=45)\end{array}$ & $\begin{array}{c}439.468 \\
(311.5332 ; 585.622) \\
\end{array}$ & $U=284.5, p<0.01$ & $\begin{array}{l}U_{1-2}=1557, p_{1-2}<0.01 \\
U_{2-3}=834, p_{2-3}=0.346\end{array}$ \\
\hline $\begin{array}{c}\text { AIT } \\
(n=42)\end{array}$ & $\begin{array}{c}395.5947 \\
(285.6217 ; 595.2213) \\
\end{array}$ & $U=230, p<0.01$ & $\begin{array}{l}U_{1-3}=1736, p_{1-3}<0.01 \\
U_{2-3}=834, p_{2-3}=0.346\end{array}$ \\
\hline $\begin{array}{l}\text { Control } \\
\text { group } \\
(n=20)\end{array}$ & $\begin{array}{c}517.8108 \\
(419.1486 ; 809.2243)\end{array}$ & & \\
\hline
\end{tabular}

Note: ${ }^{1} p<0.05$ - the difference is statistically significant between groups;

${ }^{2} U_{1-2^{\prime}} p_{1-2}$ - the difference between GERD + AIT group and isolated GERD;

$U_{1-3}, p_{1-3}$ - the difference between GERD + AIT group and isolated AIT;

$U_{2-3}, p_{2-3}$ - the difference between GERD and AIT groups.

Table VI. MnSOD activity in the examined patients, ng/ml

\begin{tabular}{|c|c|c|c|}
\hline Groups & MnSOD activity, ng/ml & $\begin{array}{l}\text { Significance of differences } \\
\text { compared with control group }\end{array}$ & $\begin{array}{c}\text { Significance of differences } \\
\text { between groups }{ }^{1,2}\end{array}$ \\
\hline $\begin{array}{l}\text { GERD and AIT } \\
(n=120)\end{array}$ & $\begin{array}{c}9.1965 \\
(7.248 ; 11.6385) \\
\end{array}$ & $U=386, p<0.01$ & $\begin{array}{c}U_{1-2}=108, p_{1-2}<0.01 \\
U_{1-3}=2509.5, p_{1-3}<0.01\end{array}$ \\
\hline $\begin{array}{c}\text { GERD } \\
(n=45)\end{array}$ & $\begin{array}{c}7.17 \\
(6.1056 ; 8.1948) \\
\end{array}$ & $p>0.05$ & $\begin{array}{c}U_{1-2}=108, p_{1-2}<0.01 \\
U_{2-3}=915.5, p_{2-3}=0.802\end{array}$ \\
\hline $\begin{array}{c}\text { AIT } \\
(n=42)\end{array}$ & $\begin{array}{c}7.5515 \\
(5.8327 ; 9.2338) \\
\end{array}$ & $p>0.05$ & $\begin{array}{l}\mathrm{U}_{1-3}=2509.5, \mathrm{p}_{1-3}<0.01 \\
\mathrm{U}_{2-3}=915.5, \mathrm{p}_{2-3}=0.802\end{array}$ \\
\hline $\begin{array}{l}\text { Control } \\
\text { group } \\
(n=20)\end{array}$ & $\begin{array}{c}4.472 \\
(3.701 ; 5.2325)\end{array}$ & & \\
\hline
\end{tabular}

Note: ${ }^{1} p<0.05$ - the difference is statistically significant between groups;

${ }^{2} U_{1-2^{\prime}} p_{1-2}$ - the difference between GERD + AIT group and isolated GERD;

$U_{1-3^{\prime}} p_{1-3}$ - the difference between GERD + AIT group and isolated AIT;

$U_{2-3^{\prime}}^{1-3^{\prime}} \mathrm{p}_{2-3}$ - the difference between GERD and AIT groups.

\section{RESULTS}

In the analysis of the main complaints in patients with GERD, certain differences in the incidence of the leading symptoms characterizing the exacerbation of esophagitis were revealed. However, it should be noted that significant differences were observed only when comparing the incidence of belching. Thus, in patients with isolated GERD, this symptom occurred only in $6(13.3 \%)$ cases, whereas $63(52.5 \%)$ patients complained of belching accompany- ing combined pathology $\left(\chi^{2}=20.6343, \varphi^{*}=5, \mathrm{p}<0.00001\right)$ (Tab II).

The study of the designated student cohort on tobacco smoking experience as one of the leading risk factors revealed that pack/years indicator in patients with comorbid pathology was $3.5 \pm 1.1$ and $3.9 \pm 1.2$ pack/years in the comparison group. In the main group, the number of active smokers was $31(25.8 \%)$, the vast majority were male (20 patients $-64.5 \%), 34(28.3 \%)$ have been smoking in the 
past; the rest did not indicate the presence of this risk factor. There were 13 (28.9\%) patients in the comparison group of active smokers, among them -8 men (61.5\%); 14 patients (31.1\%) were smokers in the past. The statistical analysis revealed no significant differences in the distribution of the smoking factor as a whole by groups $\left(\chi^{2}=0.156, \mathrm{p}=0.693\right)$ and by sex $\left(\chi^{2}=0.035, \mathrm{p}=0.852\right)$.

With a more in-depth analysis of the expressiveness of GERD clinical symptoms, the image was somewhat different. Among the clinical manifestations, the leading symptom was heartburn, which occurred in all patients examined, but had different frequency, intensity, and time dependence when compared between groups.

Thus, according to the questionnaire of patients using the international standardized questionnaire GerdQ, the course of GERD on the background of AIT was accompanied by a significant redistribution towards an increase in the incidence of heartburn, sleep disorders due to nighttime episodes of heartburn, and, as a consequence, the use of additional medicines to relieve symptoms. Thus, in the presence of AIT, heartburn occurred 4-7 times a week in $77.5 \%$ of patients versus $60 \%$ in patients with isolated GERD, nighttime episodes of heartburn with sleep disorders - in $65.0 \%$ and $31.1 \%$, respectively, the need to use additional medications to relieve symptoms - in $43.3 \%$ and $20 \%$ of patients, respectively (Tab III).

A detailed analysis of the severity of the leading symptoms by the sum of points in the GerdQ questionnaire revealed a significantly higher degree of heartburn in patients with GERD and AIT ( $\mathrm{p}=0.03)$. The presence of significantly more pronounced sleep disorders $(p<0.01)$ and the need to use additional medications $(\mathrm{p}<0.01)$ in $\mathrm{pa}-$ tients with comorbid pathology testified to the significant impact of AIT on the quality of life of patients, which may be manifested by a clear change in the subjective perception of the patient's physical and psychosocial status, and have a negative impact on the course of the disease and treatment effectiveness (Tab IV).

Thus, despite the fact that AIT manifestations had no clinical implications, the superposition of immune changes contributed to the worsening of clinical symptoms of GERD in the main group of patients, which was probably due to the intensification of inflammatory processes and the imbalance of redox mechanisms by the presence of autoimmune component.

This thesis was confirmed in the study of the total antioxidant activity of the patients' serum. There was found a significant decrease relative to normal in all groups of patients, which confirmed the presence of an active inflammatory component in the course of the disease, the occurrence and intensity of which led to the depletion of the first phase of antioxidant defence (Tab V).

Reduction of total antioxidant activity of blood allowed to state that both diseases with a chronic nature of the course lead to a depletion of the defence system, thereby contributing to the transition of physiological apoptosis to pathological. As shown in Table V, the major changes in the TAA indicators were determined by the combination of nosological forms, which can be considered not as a simple summation of these indicators, but as a new quality of the pathogenetic link of endotoxicosis syndrome.

The determination of MnSOD activity established its increase in all patients (Tab VI), which was the result of intracellular activation of the antioxidant defence system.

The study of TAA and MnSOD indicators, taking into account the lesion form of esophageal mucosa, clinical manifestations of the disease, age and sex of patients and duration of the disease showed no significant differences. Correlation analysis found the correlation dependence of TAA and MnSOD only on the experience of smoking: increase in the pack/years indicator was accompanied by more significant inhibition of TAA $(r=-0.812, \mathrm{p}<0.01)$ and hyperactivation of $\mathrm{MnSOD}(\mathrm{r}=0.784, \mathrm{p}<0.01)$.

\section{DISCUSSION}

MnSOD activity is considered the activation indicator of the second phase of xenobiotics detoxification, of its local level. Thus, increased MnSOD activity in the examined patients can be considered as a result of the initiation of the local defence mechanisms. After all, the MnSOD contained in the prokaryotic matrix protects against endogenous superoxide anion radicals, which are one of the major prooxidants in the cell, so the enhancing of MnSOD synthesis leads to the modulation of oxidative stress at the local level and plays one of the leading roles in the organism's antioxidant defence $[4,5,6]$.

The dissonance between TAA and MnSOD can be explained by the short history of diseases and the high reactivity of the organism, which is characteristic of young people. That is, in the presence of GERD and AIT in young people, the compensatory reserves of antioxidant defence at the local intracellular level are "saved".

Oxidative stress is one of the most important links in the multifactorial pathogenesis of GERD and causes the expansion of the intercellular spaces in the esophageal mucosa and disrupts its barrier function [17]. The importance of lipid peroxidation in local damage to the esophageal mucosa in GERD deserves increased attention. An in vitro study has shown that as a result of the action of acid and bile salts, the enzyme NADPH oxidase is activated in the squamous epithelial cells of the esophagus, which increases the production of ROS. The latter inactivate prolyl hydroxylases and promote the accumulation of hypoxia-inducible factor and the production of pro-inflammatory molecules [18].

The activation of lipid peroxidation processes at the local (esophagus) level in patients with GERD is accompanied by overproduction of ROS by epithelial cells of the esophageal mucosa due to the action of refluctate, which, in turn, further damages the mucous membrane $[19,20]$. Excessive concentrations of free oxygen radicals in conditions of a lack of antioxidants such as reduced glutathione and SOD damage DNA and promote the development of esophageal adenocarcinoma [21]. There is a dependence of lipid peroxidation processes on the severity of GERD: the malonyldialdehyde content in the esophageal mucosa of patients with 
reflux esophagitis exceeded that in patients with non-erosive GERD, and the decrease in total SOD activity is inversely proportional to the severity of damage to the esophageal mucosa [22]. Oxidative stress accompanies thyroid diseases, while the mechanisms of its implementation depend on the functional state of the gland: in hyperthyroidism, the leading link is the overproduction of ROS, and in hypothyroidism, the low availability of antioxidants [23]. Meanwhile, the analysis of studies of the last decade indicates much more complex mechanisms of the formation of oxidative stress in thyroid pathology and its role in the pathogenesis of these diseases. It is known that an excess of thyroid stimulating hormone directly contributes to oxidative stress [24].

Activation of lipid peroxidation is observed in both overt hypothyroidism and its subclinical form, as indicated by an increase in the level of malonyldialdehyde and carbonyl proteins [25]. The hyperthyroid state is characterized by an increase in the rate of cellular metabolism and, consequently, an increase in the number of free radicals, the level of peroxides, and the like. Redox imbalance due to hyperthyroidism causes adaptation of antioxidant systems with an increase or decrease in the activity of antioxidant enzymes, and also activates the extracellular signal-regulated kinase $1 / 2$ signaling pathway responsible for the activation of $T$ cells, proliferation of endothelial cells during angiogenesis, etc. [26]. Thus, thyroid hormones can have a protective role, affecting the content of antioxidants, on the other hand, hypothyroidism can increase oxidative stress [27].

\section{CONCLUSIONS}

The presence of concomitant AIT in patients with GERD among the student population contributes to some deviations in the clinical characteristics of the disease, which is manifested by a significant increase in the frequency and intensity of heartburn, sleep disorders and the use of additional medications to relieve symptoms. The data obtained indicate a significant impact of AIT on the quality of life of patients, which can be manifested by clear changes in the subjective perception by the patient of his physical and psychosocial status.

The course of both GERD and AIT in students is accompanied by the inhibition of total antioxidant activity, as a consequence of damage to the cell membrane and the «failure» of the first general systemic level of control of toxic radicals formation. Herewith, the combination of these nosologies leads to a significant deepening of the degree of TAA deviation.

In patients with both isolated GERD and AIT, and with their comorbidity, the activation of MnSOD, a component of the second phase of xenobiotic detoxification, was determined. The local level of MnSOD action and the mitochondrial intracellular arrangement of the enzyme suggest that there are reserves of the antioxidant system.

\section{REFERENCES}

1. Kostyuk V.A., Potapovich A.I. Mechanisms of the suppression of free radical overproduction by antioxidants. Front Biosci (Elite Ed). 2009;1:179-188.
2. Ghiselli A., Serafini M., Natella F. et al. Total antioxidant capacity as a tool to assess redox status: critical view and experimental data. Free Radic Biol Med. 2000;29:1106-1114.

3. Wang Y., Branicky R., Noë A. et al. Superoxide dismutases: Dual roles in controlling ROS damage and regulating ROS signaling. J Cell Biol. 2018:217(6):1915-1928.

4. Candas D., Li J.J. MnSOD in oxidative stress response-potential regulation via mitochondrial protein influx. Antioxid Redox Signal. 2014;20(10):1599-1617.

5. Bresciani G., da Cruz I.B., González-Gallego J. Manganese superoxide dismutase and oxidativestress modulation. Adv Clin Chem. 2015;68:87-130.

6. Holley A.K., Bakthavatchalu V., Velez-Roman J.M. et al. Manganese superoxide dismutase: guardian of the powerhouse. Int J Mol Sci. 2011;12(10):7114-7162.

7. El-Serag H.B., Sweet S., Winchester C.C. et al. Update on the epidemiology of gastro-oesophageal reflux disease: a systematic review. Gut. 2014;63:871-880.

8. Poddar U. Gastroesophageal reflux disease (GERD) in children. Paediatr Int Child Health. 2019;39(1):7-12.

9. Martigne L., Delaage P.H., Thomas-Delecourt F. et.al. Prevalence and management of gastroesophageal reflux disease in children and adolescents: a nationwide cross-sectional observational study. Eur J Pediatr. 2012;171(12):1767-1773.

10. Halawani H.M., Ali Naji A.N., Alahmari M.S. et al. A Literature Review on the Incidence of Autoimmune Thyroid Diseases. EC Endocrinology and Metabolic Research. 2017;1(1): 10-18.

11. Iddah M.A., Macharia B.N. Autoimmune thyroid disorders. SRN Endocrinol 2013; 2013:509764.

12. Lee H.J., LiC.W., Hammerstad S.S. et al. Immunogenetics of autoimmune thyroid diseases: A comprehensive review. Jutoimmun. 2015;64:82-90.

13. Aversa T., Corica D., Zirilli G. et al. Phenotypic Expression of Autoimmunity in Children With Autoimmune Thyroid Disorders. Front Endocrinol (Lausanne). 2019;10:476.

14. Wiersinga W.M. Clinical Relevance of Environmental Factors in the Pathogenesis of Autoimmune Thyroid Disease.Endocrinol Metab (Seoul). 2016;31(2):213-222.

15. Vakil N., van Zanten S.V., Kahrilas P. et al. Global Consensus Group. The Montreal definition and classification of gastroesophageal reflux disease: a global evidence-based consensus. Am J Gastroenterol. 2006;101(8):1900-1943.

16. Jones R., Junghard 0. , Dent J. et al. Development of the GerdQ, a tool for the diagnosis and management of gastro-oesophageal reflux disease in primary care. Aliment Pharmacol Ther. 2009;30(10):1030-1038.

17. Ito H., lijima K., Ara N. et al. Reactive nitrogen oxide species induce dilatation of the intercellular space of rat esophagus. Scand J Gastroenterol. 2010;45(3):282-91.

18. Huo X., Agoston A.T., Dunbar K.B. et al. Hypoxia-inducible factor-2a plays a role in mediating oesophagitis in GORD. Gut. 2017;66(9):1542-1554.

19. Yanaka A. Role of NRF2 in protection of the gastrointestinal tract against oxidative stress. J Clin Biochem Nutr. 2018;63(1):18-25. doi:10.3164/ jcbn.17-139

20. Giri A.K., Rawat J.K., Singh M., Gautam S. Effect of lycopene against gastroesophageal reflux disease in experimental animals. BMC Complement Altern Med. 2015;15:110.

21. Kwiecien S., Jasnos K., Magierowski M. et al. Lipid peroxidation, reactive oxygen species and antioxidative factors in the pathogenesis of gastric mucosal lesions and mechanism of protection against oxidative stress - induced gastric injury. J Physiol Pharmacol. 2014;65(5):613-622. 
22. Deng Y., Pan L., Qian W. Associations between the severity of reflux esophagitis in children and changes in oxidative stress, serum inflammation, vasoactive intestinal peptide and motilin. Exp Ther Med. 2019;18(5):3509-3513.

23. Mancini A., Di Segni C., Raimondo S. et al. Thyroid Hormones, Oxidative Stress, and Inflammation. Mediators Inflamm. 2016;2016:6757154. doi:10.1155/2016/6757154

24. Dardano A., Ghiadoni L., Plantinga Y. et al. Recombinant human thyrotropin reduces endothelium-dependent vasodilation in patients monitored for differentiated thyroid carcinoma. Journal of Clinical Endocrinology \& Metabolism. 2006;91(10):4175-4178.

25. Haribabu A., Reddy V. S., Pallavi C. et al. Evaluation of protein oxidation and its association with lipid peroxidation and thyrotropin levels in overt and subclinical hypothyroidism. Endocrine. 2013;44(1):152-157.

26. Araujo A.S., Fernandes T., Ribeiro M.F., Khaper N. Redox regulation of myocardial ERK 1/2 phosphorylation in experimental hyperthyroidism: role of thioredoxin-peroxiredoxin system. J Cardiovasc Pharmacol. 2010;56(5):513-517.

27. Mancini A., Di Segni C., Raimondo S. et al. Thyroid hormones, oxidative stress, and inflammation. Mediators Inflamm. 2016;2016:1-12.

This study is a fragment of the research work "Mechanisms offormation of gastroesophageal reflux disease with concomitant pathology and development of methods of its pathogenetic correction in students» (0110U002441)

\section{ORCID and contributionship:}

Tamara M. Pasiieshvili: 0000-0002-7079-4761 A, B, C, D, E, F

Natalia M. Zhelezniakova: 0000-0002-5786-9378 A, B, D, E,

Lyudmila M. Pasiyeshvili: 0000-0001-7527-782X ${ }^{A, E, F}$

Olga M. Kovalyova: 0000-0003-3410-6623 A, D, E, F

\section{Conflict of interest:}

The Authors declare no conflict of interest.

\section{CORRESPONDING AUTHOR \\ Tamara M. Pasiieshvili \\ Kharkiv National Medical University \\ 4 Nauky Avenue, 61022 Kharkiv, Ukraine \\ tel: +380505950303 \\ e-mail:pasotoma2017@gmail.com}

Received: 10.05 .2020

Accepted: 16.10 .2020

A - Work concept and design, B - Data collection and analysis, C - Responsibility for statistical analysis, $\mathbf{D}$-Writing the article, $\mathbf{E}$-Critical review, $\mathbf{F}$ - Final approval of the article 